\title{
COVID-19, Oil Price, Bitcoin, and US Economic Policy Uncertainty: Evidence from ARDL Model
}

\author{
Hanan Naser ${ }^{1}$ \\ ${ }^{1}$ College of Businee and Managemenr, American University of Bahrain, Riffa, Bahrain \\ Correspondence: Hanan Naser, College of Businee and Managemenr, American University of Bahrain, Riffa, \\ Bahrain.
}

Received: August 3, 2021

doi:10.5539/ijef.v13n11p92
Accepted: October 22, 2021

Online Published: October 25, 2021

URL: https://doi.org/10.5539/ijef.v13n11p92

\begin{abstract}
The pandemic of coronavirus (COVID-19) creates fear and uncertainty causing extraordinary disruption to financial markets and global economy. Witnessing the fastest selloff in the American stock market in history with a plunge of more than $28 \%$ in S\&P 500 has increased the volatility of global financial market to exceed the level observed during the financial crisis of 2008. On the other hand, Bitcoin value has shown considerable stability in the last couple of months peaking at $\$ 10,367.53$ in the mid of February 2020. In this context, the aim of this paper is to investigate the impact of COVID-19 numbers on Bitcoin price taking into consideration number of controlling variables including WTI-oil price, S\&P 500 index, financial market volatility, gold prices, and economic policy uncertainty of the US. To do so, ARDL estimation has been applied using daily data from December 31, 2019 till May 20, 2020. Key findings reveal that the daily reported cases of new infections have a marginal positive impact on Bitcoin price in the long term. However, the indirect impact associated with the fear of COVID-19 pandemic via financial market stress cannot be neglected. Bitcoin can also serve as a hedging tool against the economic policy uncertainty in the long term. In the short run, while the returns of economic policy uncertainty have no impact on Bitcoin price, the growth in the new cases of COVID-19 infection and returns of financial market volatility have more positive significant impact on Bitcoin returns.
\end{abstract}

Keywords: bitcoin, COVID-19, stock prices, oil prices, policy uncertanity

\section{Introduction}

Although the outbreak of the novel coronavirus (COVID-19) has severely affected Wuhan, China, since late December 2019, the World Health Organization (WHO) has just announced that the outbreak is officially a pandemic on March 11 (Note 1). Precisely, WHO has released the first coronavirus monitoring report on the $21^{\text {st }}$ January, 2020, where the virous has widely spread over more than 100 countries with more than 100,000 confirmed infected cases. The focal shift in the infections went from China to Europe in early March, where the Unites States has reported the first diagnosed case in April 2020. By $19^{\text {th }}$ May 2020, the total infected people reached 4982, 306 with 324,508 death cases (Note 2).

Therefore, the fear of the fast transmission of COVID-19 virus has pushed the governments to impose quarantine restrictions on a wide scale. Like other several crises, the repercussion of coronavirus generates a lot of uncertainty in the real economy and financial market. According to the Asian Development Bank (ADB), the coronavirus pandemic could cost a loss of $\$ 5.8 \mathrm{tn}-\$ 8.8 \mathrm{tn}$ in the global economy (Note 3 ). The overall demand has significantly decreased since the start of the pandemic, followed by fears in mobility among workers and tourists, which have increased the level of unemployment in many countries including the US. The panic caused by the coronavirus pandemic has also triggered a clear decline in global trade and thus generated shortage in local food supply. The spill over of the global lockdown has created more stress on the financial markets and thus widened the swing of many commodity prices. Looking at the crude oil market, the variation in crude oil prices has witnessed a great swing from $\$ 150 /$ barrel in 2014 to $\$ 30$ in 2020 due to many factors as explained in literature (Note 4). Recently, Saudi Arabia has started an oil price war on March 09, 2020, by flooding the market with oil despite the prior knowledge of the anticipated strong decrease in the global demand for oil. This has caused an enormous shock, where the prices have collapsed by more than $20 \%$ in one day. The Organization of Oil Exporting Countries (OPEC) has claimed that the current collapse in oil prices is the biggest since the Gulf War of 1991 (OPEC, 2020a). 
The fear associated with the high transmission of coronavirus, the slowdown in the global economy, and the failure of OPEC to agree on a production quota for crude oil have quickly spilled over the financial market and thus caused a tremendous crash on 12 March 2020. Between February 20 and March 19, the S\&P 500 index fell by $28 \%$ (from 3,373 to 2,409), while the CBOE Volatility Index (VIX) -the most common metric for measuring the expected volatility of the US stock market- hit 82 and accordingly exceeded the spike observed during the Great Financial Crisis of 2008-2009. Despite the arguments which suggest that the Economic Policy Uncertainty (EPU) is the main controller that influence the VIX (Antonakakis et al., 2013; Chen \& Chiang 2020; Zhenghui \& Junhao, 2019), many investors may suffer from a great wealth loss and thus escaped to other investment platforms. At the same period, the prices of Bitcoin have witnessed a dramatic jump which has not been experienced for almost three months, which has trigged the attention of many researchers in the field. For instance, Chen et al. (2020) study the impact of fear sentiment caused by the coronavirus pandemic on Bitcoin price dynamics. The results show that market volatility has been worsened by fear sentiment as the result of an increase in search interest in coronavirus. Moreover, negative Bitcoin returns, and high trading volume could be explained by fear sentiment regarding the coronavirus. In another study created by Corbet et al. (2020), the relationship between the main Chinese stock markets and Bitcoin during this period of enormous financial stress has been investigated. They have provided several observations as to why this situation occurred. Such dynamic correlations during periods of stress present further evidence to cautiously support the validity of the development of this new financial product within mainstream portfolio design through the diversification benefits provided. In this context, Bitcoin can act as a 'safe haven' asset within the outbreak of coronavirus taking into consideration the downturn of the fragile financial system (Klein et al., 2018). Recently, many studies have proposed that the Bitcoin can play the role of a safe haven for many reasons such as being independent from the monetary policy, the potential to be a store of value and having weak correlations with traditional assets (Shahzad et al., 2019). But in general, Bitcoin shares common features with traditional assets and accordingly the extrapolation of nexus among traditional assets and cryptocurrencies received a great interest among many researchers (Kyriazi, 2020). Klein et al. (2018) highlight the role of Bitcoin as an investment asset and claim that it has been described as the new gold. Other studies were more precise towards understanding the relationship between cryptocurrencies and COVID-19 such as Mnif et al. (2020). They have studied the level of cryptocurrency efficiency through multifractal analysis before and after the coronavirus pandemic. The main findings show that COVID-19 has a positive impact on the cryptocurrency market efficiency.

Under the light of the global lockdown of coronavirus pandemic, the aim of this study is to investigate the impact of the growth of daily COVID-19 cases on the return of Bitcoin in the short run, while controlling for the role of returns on crude oil prices (WTI), returns of US S\&P 500 stock prices, changes in both financial stress and volatility (VIX index), and the US economic policy uncertainty (EPU). Long run relationship between the suggested variables has also been investigated. To our knowledge, this is the first paper that attempts to scrutinize the above relationships. To do so, daily data for the targeted indicators are collected and Autoregressive Distributed Lag (ARDL) is applied to examine both short and long-term relationship.

The rest of the paper is organized as follows. Section 2 represents the data, model and methodology, Section 3 summarizes the main results and discussion, while Section 4 briefs the concluding remarks.

\section{Method}

\subsection{Data}

Since the aim of this paper to investigate the relationship between COVID-19 new cases and Bitcoin prices, total daily infected cases have been extracted from the database of WHO reports starting with 31 December 2020 till 20 May 2020 (142 observations). Bitcoin prices (BTC) are extracted from Yahoo Finance. The study includes several control variables including:

(a) S\&P 500 Stock Prices: Since stock prices are key indicators of both macroeconomic and financial development, many recent research papers have investigated the relationship between them. For example, Ciaian et al. (2016) and Van Wijk (2013) noted that the migration of traditional investors to cryptocurrencies has raised the correlation between Bitcoin and stock prices.

(b) Financial Volatility Index (VIX): The need of a common benchmark of volatility that may work as a reference point of market exposure for investors has encouraged the use of VIX index in many financial market studies.

(c) Oil prices: The oil prices are also considered as a determinant of Bitcoin prices (Ciaian et al., 2016). Oil prices are attributed to inflationary pressure in an economy. Thus, the price of Bitcoins may be aligned with potential change in general price level that are associated with signals of oil price oscillations (Ciaian et al., 
2016).

(d) Economic Policy Uncertainty: The US EPU has been included as another critical determinant of Bitcoin prices. The EPU is a newspaper-based index of uncertainty constructed from News Bank Access World News Database (Note 5). This index reflects the overall viability of the business environment and investment and investment prospects; thus, this variable has gained considerable recognition in financial literature as an indicator of risk (Al-Yahyaee et al., 2019). Demir et al. (2018) analyzes the predictive power of EPU on Bitcoin returns and concludes that Bitcoin is a hedging tool for economic uncertainty.

Daily data of the above variables have been collected to cover the same period. WTI oil prices are obtained from the US energy Information Administration (EIA), where both the US daily stock price index for S\&P 500 has been extracted from Yahoo Finance. In addition, the financial volatility (VIX) data obtained from Chicago Board Options Exchange (CBOE) and finally the statistics of US Economic Policy Uncertainty (US-EPU) which is news- based index is extracted from Baker et al. (2016) (Note 6).

Figure 1 shows that the dramatic fall in oil prices in reaction to the novel coronavirus pandemic. In fact, due to the lockdown measures that aim to contain the spread of COVID-19, the global demand for oil was predicted to drop globally. The International Energy Agency (IEA) has predicted that the drop in global demand during April will be 30\% less than the original expectations. The collapse of oil prices during the pandemic has accordingly gone to its lowest price on 20 April 2020 to make the history. As discussed above, the spillover of the shock had a widespread on the global stock market, where Figure 2 reveals how the US S\&P 500 price index has witnessed a remarkable plunge and thus increased the stress and volatility in the financial market as shown in Figure 3. The reaction of the EPU to the pandemic has been also notable as shown in Figure 4. The instability shown in Figure 5 went along with the increase in demand for Bitcoin and thus influenced the prices as shown in Figure 6. Table 1 shown below represents the basic statistics for the raw data used and the returns for variables used in the study. All variables are converted into natural logs for the empirical investigation. The summary statistics considered include mean, maximum, minimum, standard deviation, skewness, and kurtosis. The mean of the summary statistics indicates positive average returns for both Bitcoin and oil, while the average S\&P 500 returns is negative. The positive average bitcoin returns could be suggestive of a relatively average improved performance. On the other hand, the stock prices of S\&P 500 returns experienced an overall average decline due to the outbreak of COVID-19. The standard deviation which depicts a more volatile Bitcoin and crude oil returns than S\&P 500. Finally, all the series returns are negatively skewed for the full sample during the pandemic, while oil and VIX are positive. The high kurtosis values suggest that all the series are leptokurtic.

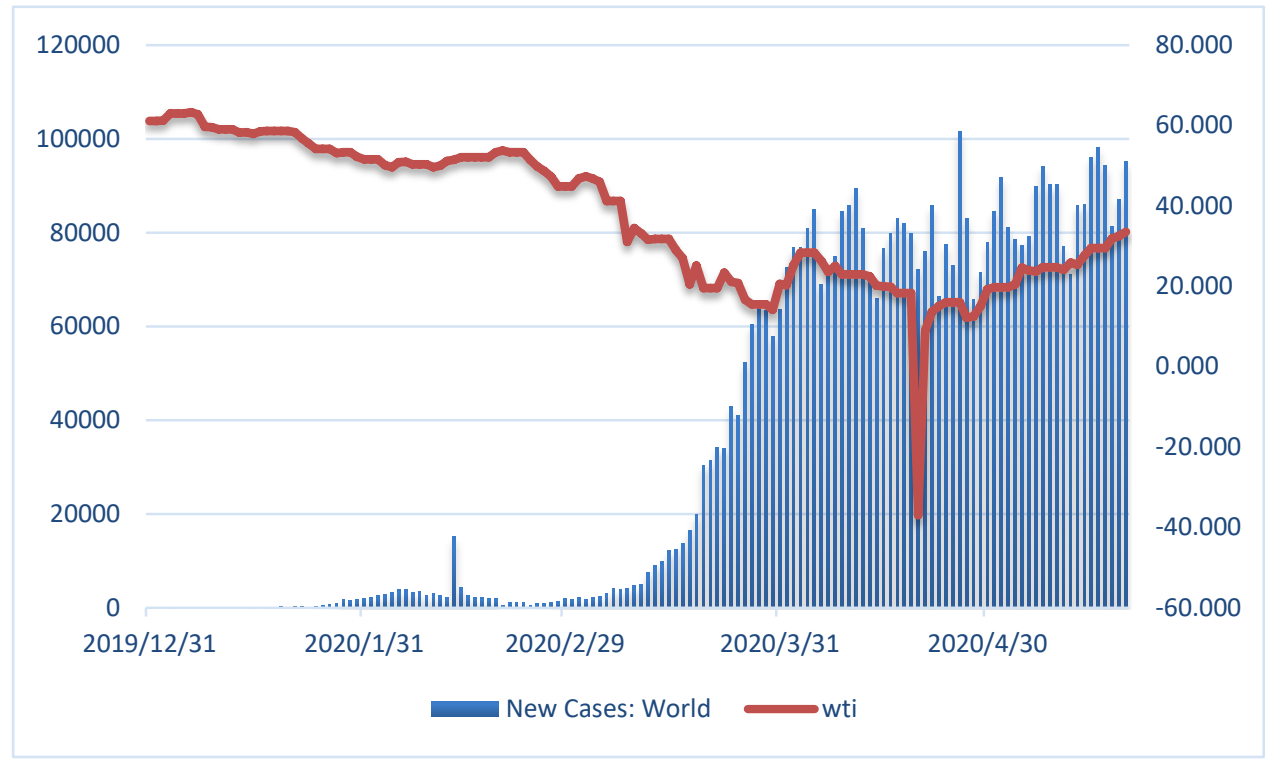

Figure 1. COVID-19 new infection cases and WTI prices 


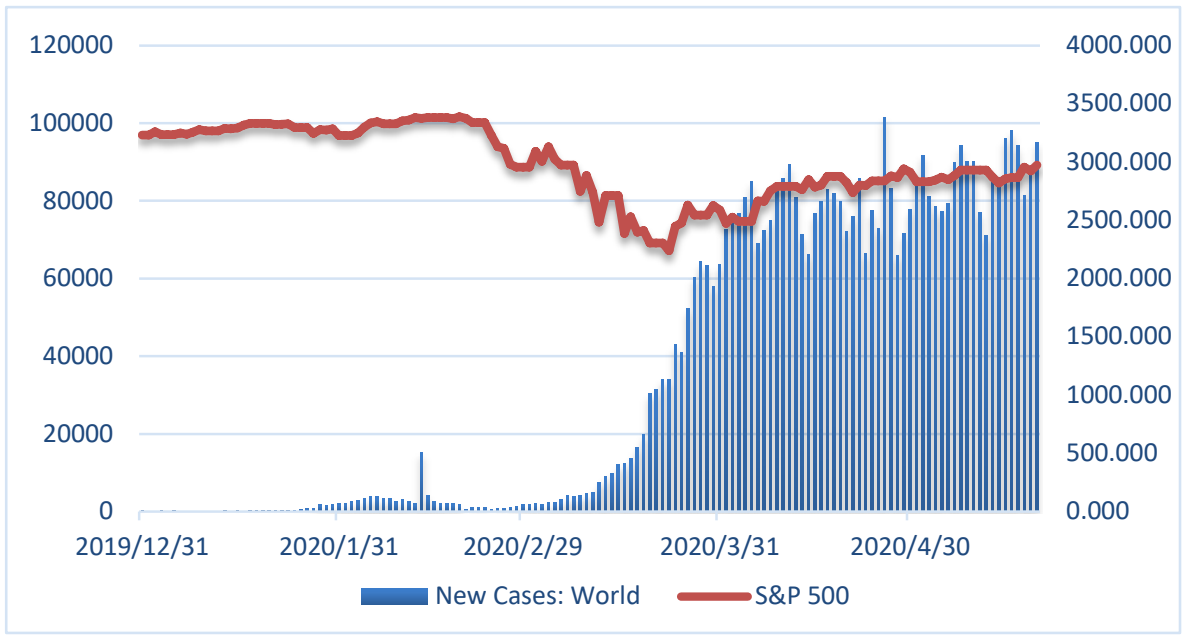

Figure 2. COVID-19 new infection cases and US S\&P 500 prices

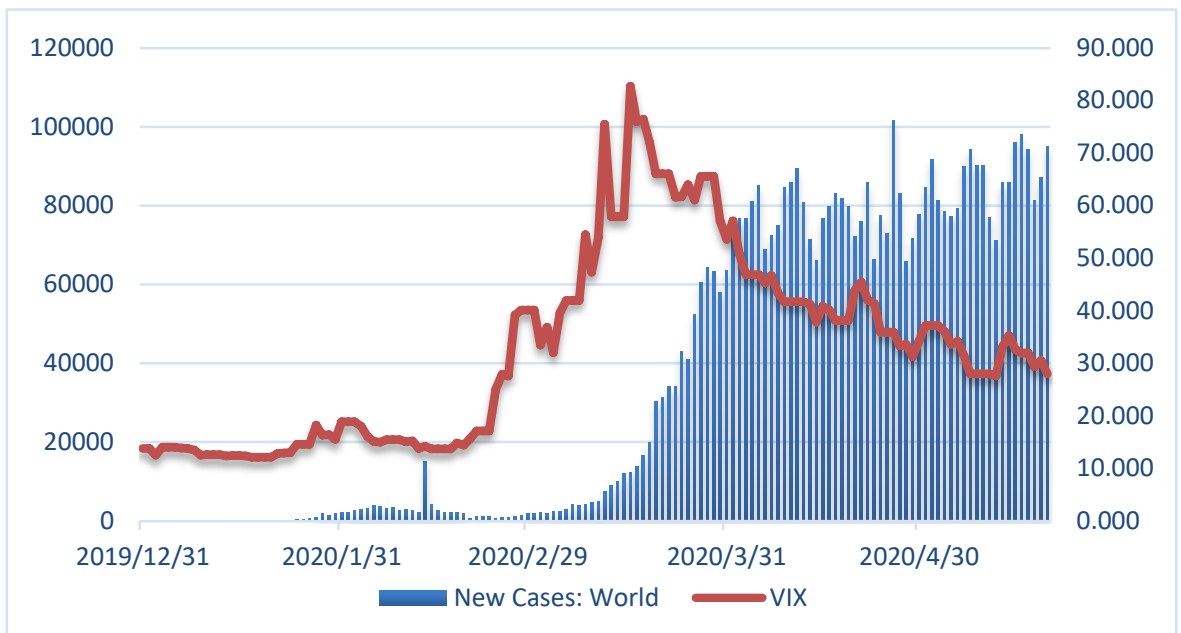

Figure 3. COVID-19 new infection cases and VIX

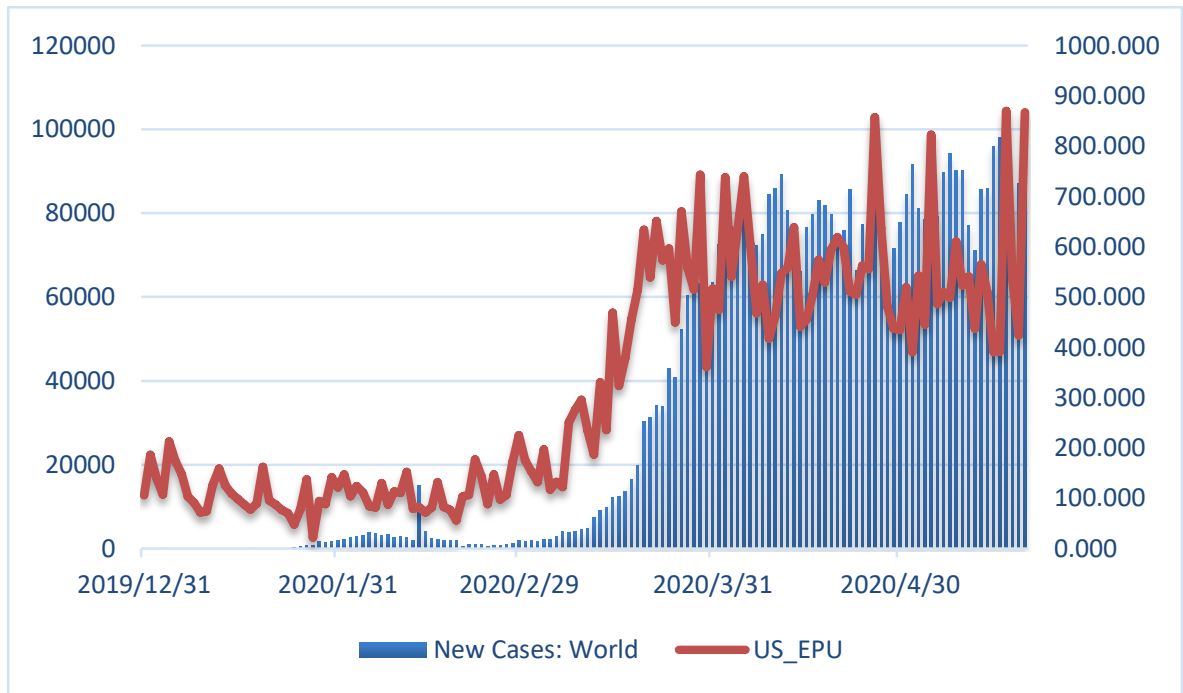

Figure 4. COVID-19 new infection cases and US EPU 


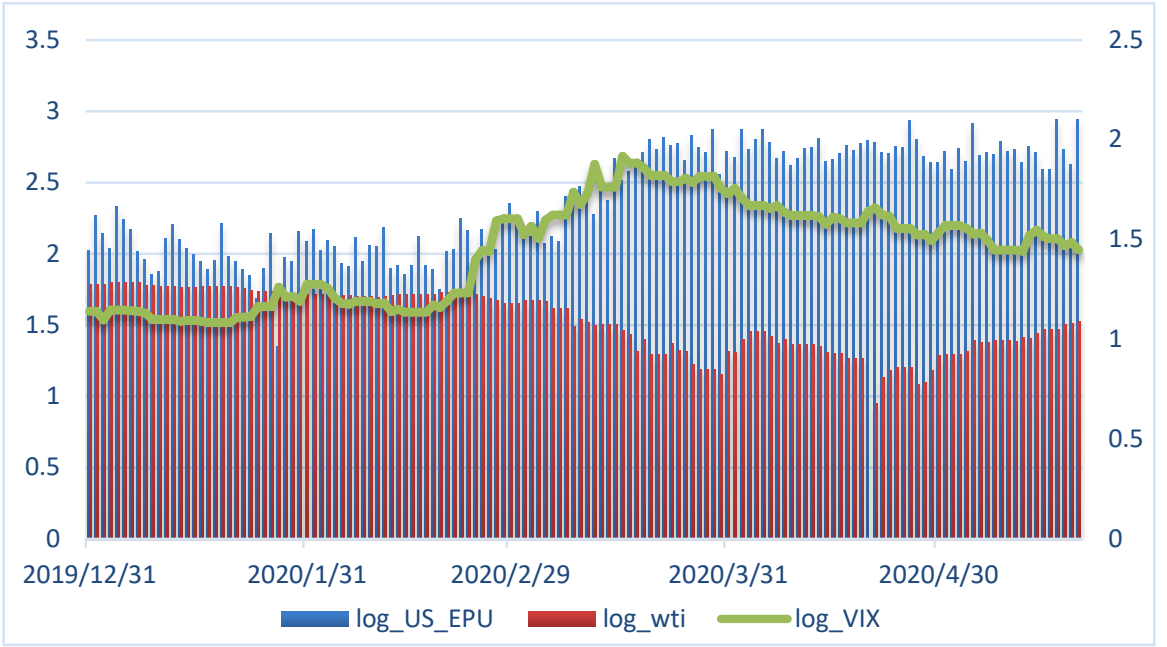

Figure 5. Dynamics of US EPU, Oil price (WTI) and Financial Stress (VIX)

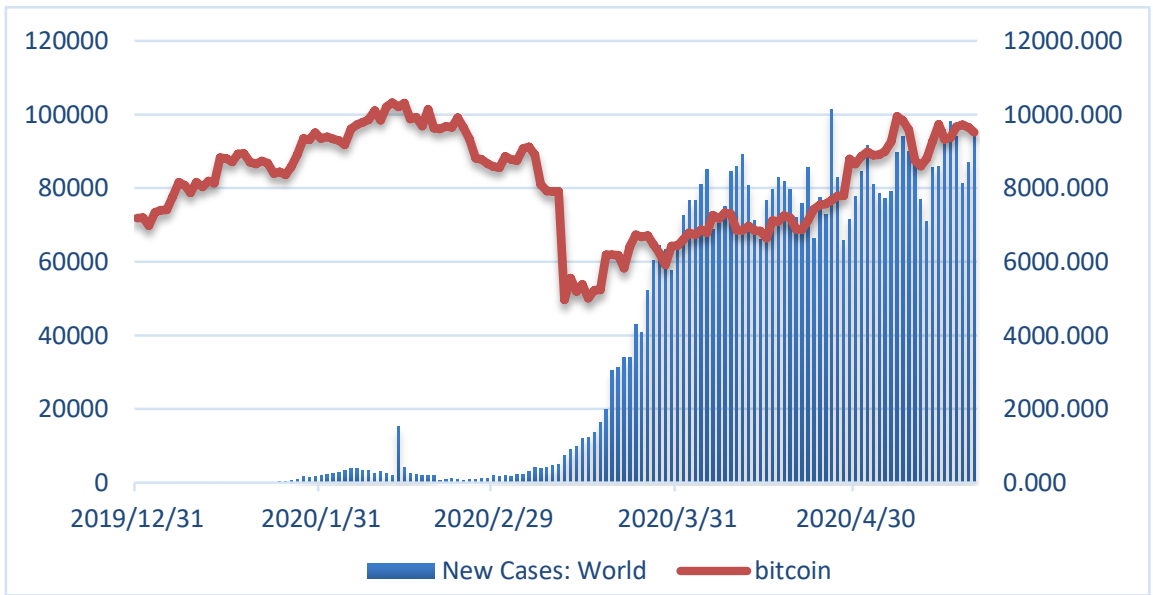

Figure 6. COVID-19 new infection cases and Bitcoin Price (BP)

Table 1. Descriptive statistics

\begin{tabular}{lcccccc}
\hline Variables Description & Mean & St. deviation & Minimum & Maximum & Skewness & Kurtosis \\
\hline Bitcoin & 8183.59 & 1347.599 & 4970.788 & 10326.05 & -0.448 & 2.262 \\
COVID-19 & 34234.8 & 37593.54 & 0 & 101445 & 0.435 & 1.374 \\
WTI & 37.247 & 17.4965 & -36.98 & 63.27 & -0.455 & 3.419 \\
S\&P 500 & 2977.94 & 309.302 & 2237.4 & 3386.15 & -0.384 & 2.121 \\
VIX & 32.71 & 18.09709 & 12.1 & 82.69 & 0.654 & 2.579 \\
US EPU & 324.816 & 227.3582 & 22.25 & 869.86 & 0.439 & 1.929 \\
\hline
\end{tabular}

\subsection{ARDL Model}

Following the approach that was developed by Pesaran and Pesaran (1997), Pesaran and Smith (1998), Pesaran and Shin (1999), and Pesaran et al. (2001), this paper uses the Autoregressive Distribution Lag Model (ARDL) to investigate the linkage among the proposed variables. To be specific, the pioneering work of Pesaran and Pesaran (1997) has developed an approach that allows the estimation to go from general into more specific modelling. This approach called Autoregressive Distributed Lag Model (ARDL), where enough lags should be utilized to capture the specifications of the data generation process. The literature has pointed many advantages for using this approach, but the primary advantage that has been reported Pesaran and Pesaran (1997) is that the integration of the variables that are used in the estimation could be either I (0), or I (1) or even fractionally cointegrated. In addition, the short and long-term equilibrium features that can be derived from the ARDL can be dedicted by the error correction model (ECM) usind a simple linear transformation. Another unique feature that has been claimed by Pesaran and Shin (1999) is the appropriateness of ARDL for small samples that are usually 
far superior to that of the Johensen and Juselius's cointegration method. ARDL can simply accommodate the problem of endogeneity which is another concern in such estimations. To be precise, ARDL is mostly free of residual correlation and accordingly it allows for eliminating both residual correlation and endogeniety problems as claimed by Pesaran and Shin (1999). In the end, another important advantage of ARDL procedure is that the estimation is possible even when the explanatory variables are endogenous (Pesaran and Pesaran 1997; Pesaran et al., 2001).

\subsection{Methodology}

\subsubsection{Unit Root Testing}

Since many economic time series variables exhibit trending behavior or non-stationary in the mean, it is essential to examine the level of integration of each suggested variable before conducting any other cointegration test. To do so, this paper uses Augmented Dickey and Fuller (ADF) test which is an augmented version of the original Dickey and Fuller test (1979) that has been modified to accommodate more complex models with unknown orders (the augmented Dickey-Fuller test):

$$
\Delta y_{t}=\theta_{0}+\alpha_{0} t+\alpha_{1} y_{t-1}+\sum_{i=0}^{p} \theta_{i} \Delta y_{t-1}+\mu_{t}
$$

where $y_{t}$ is the variable in period $\mathrm{t} ; \Delta y_{t-1}$ is the $y_{t-1}-y_{t-2}$; the i.i.d. disturbance $\mu_{t}$ has mean 0 and variance $1 ; \mathrm{t}$ the linear time trend and $\mathrm{p}$ is the lag order. To test the null hypothesis for the presence of a unit root in $y_{t}$, the hypothesis testing that $\alpha_{1}=0$ in Equation (1) has been conducted. If $\alpha_{1}$ is significantly less than zero, the null hypothesis of a unit root is rejected. Results of ADF are obtained for both level and first differenced variables as a treatment for non-stationary data. In addition, Phillips and Perron (1988) unit root test has been applied for robust check.

\subsubsection{ARDL Estimation}

Since the aim of this paper focuses on examining the impact of the daily new cases of COVID-19 on the Bitcoin prices taking into consideration a number of other explanatory variables that experienced a dynamic movement during the pandemic including: WTI oil prices, S\&P stock market prices, the global financial stress and volatility expressed via VIX index and the uncertainty associated with the US economic policy, a linear model into a natural $\log$ form is required. The log-linear specification can produce more consistent and efficient results than the linear model. Furthermore, the natural $\log$ model should help to persuade stationarity in the variance-covariance matrix as follows:

$$
\ln (B T C)_{t}=\mu_{0}+\mu_{1} \ln (\text { COVID - 19) })_{t}+\mu_{2} \ln W T I_{t}+\mu_{3} \ln S P 500+\mu_{4} \ln V I X_{t}+\mu_{5} \ln E P U_{t}+\varepsilon_{t} \text { (2) }
$$

where $\varepsilon_{t}$ is the regression error term and the intercept of the model is given by $\mu_{0}$. The coefficients $\mu_{0}, \mu_{1}, \mu_{2}, \mu_{3}, \mu_{4}$ and $\mu_{5}$ represent, respectively, the impacts of COVID-19 new cases, fluctuations in crude oil price (WTI), US stock market (SP500), volatility in the global financial market, and the US economic policy uncertainty (EPU).

Once the integration level is confirmed for all variables that are included in the estimation, the existence of lon-run relationship among the variables is tested using ARDL bound testing. Ultimately, the ARDL bond test has been developed by Pesaran et al. (2001) depends on an F-test that investigates the joint significance of the coefficients of the lagged level variables. In another words, the null hypothesis of the test can be represented by H0: $\mu_{1}=\mu_{1}=\mu_{2}=\mu_{3}=\mu_{4}=\mu_{5}=0$, while the alternative is that at least one $\mu$ is not equal to 0 . The constructed F-statistic is then compared to both upper and lower critical values reported by Pesaran et al. (2001). If the constructed value of the F-statistic is larger than the upper limit, then a cointegration relationship exists. If the value is smaller than the lower limit, the null cannot be rejected. If the F-statistic is between the two limits, the results are inconclusive. After establishing a cointegration relationship, Bouznit and Pablo-Romero 2016 suggest using Equation (2) to capture the dynamics of the estimated long run relationship, where the Akaike information criteria (AIC) is used to select the optimal lag length for each case. The estimated values of $\mu_{0}$ measures the long-run impact of each variable that has been included in the model over the Bitcoin (BTC). The residuals can be used as an approximation of the error correction term (ECT), which indicates the speed of the adjustment of any dis-equilibrium in the model. ECT can basically give an indication on how quickly the variables return to the long run equilibrium after any shock. ECT should have a statistically significant coefficient with a negative sign and equal or less than one. The error correction model (ECM) can be represented as below:

$$
\begin{gathered}
\Delta \ln (B T C)_{t}=\delta_{0}+\sum_{i=0}^{n} \delta_{1 \mathrm{i}} \Delta \ln \operatorname{COVID}-19_{t}+\sum_{k=0}^{q} \delta_{1 k} \Delta \ln W T I_{t}+\sum_{j=0}^{d} \delta_{2 j} \Delta \ln S P 500_{t}+ \\
\sum_{l=0}^{b} \delta_{3 l} \Delta \ln V I X_{t}+\sum_{w=0}^{y} \delta_{4 w} \Delta \ln E P U_{t}+\theta E C T_{t-1}+\varepsilon_{t}
\end{gathered}
$$




\section{Results}

As usual, time series analysis starts by testing the unit root of the variable. Results of both ADF and PP test are consistent as shown in Table 2. Variables are either integrated from first or second order, where majority are stationary at first difference level.

Table 2. Unit Root Test

\begin{tabular}{lcccc}
\hline \multirow{2}{*}{ Variable } & \multicolumn{2}{c}{ ADF } & \multicolumn{2}{c}{ PPerron } \\
\cline { 2 - 5 } & Constant & Constant and Trend & Constant & Constant and Trend \\
\hline $\ln$ BTC & -1.74 & -1.75 & -1.75 & -1.75 \\
$\ln$ COVID-19 & $-3.04 * *$ & -2.15 & -2.04 & $-4.51^{* * *}$ \\
$\ln$ WTI & -1.59 & -1.26 & -2.79 & -2.78 \\
$\ln$ SP500 & -1.33 & -1.17 & -1.44 & -1.44 \\
$\ln$ VIX & -1.42 & -0.61 & -1.35 & -0.80 \\
$\ln$ US-EPU & -1.12 & -3.09 & -1.79 & $-5.23^{* * *}$ \\
$\Delta \ln$ BTC & $-7.32^{* * *}$ & $-7.29^{* * *}$ & $-13.67^{* * *}$ & $-13.63^{* * *}$ \\
$\Delta \ln$ COVID-19 & $-6.86^{* * *}$ & $-6.88^{* * *}$ & $-31.93^{* * *}$ & $-32.65^{* * *}$ \\
$\Delta \ln$ WTI & $-6.59^{* * *}$ & $-6.72^{* * *}$ & $-12.78^{* * *}$ & $-12.92^{* * *}$ \\
$\Delta \operatorname{lnSP500}$ & $-6.87^{* * *}$ & $-6.88^{* * *}$ & $-15.44^{* * *}$ & $-15.43^{* * *}$ \\
$\Delta \ln$ VIX & $-5.87^{* * *}$ & $-5.98^{* * *}$ & $-13.25^{* * *}$ & $-13.33^{* * *}$ \\
$\Delta \ln$ US-EPU & $-10.15^{* * *}$ & $-10.12^{* * *}$ & $-23.58^{* * * *}$ & $-23.54^{* * *}$ \\
\hline
\end{tabular}

Note. (i) $* * *, * *$ and $*$ means significance at $1 \%, 5 \%$ and $10 \%$; (ii) the optimal lag selection is based on AIC information criterion; (iii) BTC refers to the bitcoin prices, (iv) COVID-19 refers to the global new cases of world.

The second important test is to investigate the existence of a long-run relationship by applying the bound tests which assume a lower bound for I( 0 ) series, and an upper bound for I(1) series and the critical values being derived from Narayan (2005). The F-statistic indicates a cointegrating relationship if the values are higher than the critical value of the upper bound. For the suggested model, ARDL of $(1,0,1,0,0,1)$ has been estimated to investigate the long and short run relationship of $B T C=f(C O V I D-19, W T I, S P 500, V I X, E P U)$. Results of the bound test shown in Table 3 reveals that the F-statistics of 3.45 is significant at $1 \%$ level.

Table 3. Results of ARDL bound testing to cointegration

\begin{tabular}{ccccc}
\hline Model & & Optimal lag structure & F - value & p-value \\
\hline & $B T C=f(C O V I D-19, W T I, S P 500, V I X, E P U)$ & $(1,0,1,0,0,1)$ & 3.450 & 0.000 \\
\hline
\end{tabular}

Following the above, results of ARDL estimation are presented in Table (4). Looking at the upper section of the table, estimates of the long-run relationship between Bitcoin, COVID-19, WTI, S\&P500, and VIX are statistically significant at $1 \%$ and $5 \%$ level, except for the EPU.

Table 4. Estimated coefficients from ARDL $(1,0,1,0,0,1)$ for model

\begin{tabular}{llll}
\hline$B T C=f(C O V I D-19, W T I, S P 500, V I X, E P U)$ & Coefficients & t-stat \\
\hline \multirow{4}{*}{ Long run estimates } & Variable & 0.001 & $1.787^{* *}$ \\
& $C O V I D-19_{t}$ & -0.014 & $-2.58^{* *}$ \\
& $W T I_{t}$ & -0.181 & $-10.67^{* * *}$ \\
& $S P 500_{t}$ & 0.209 & $-2.09^{* *}$ \\
& $V I X_{t}$ & -0.042 & -1.490 \\
& $E P U_{t}$ & 0.004 & $3.17^{* * *}$ \\
COVID $-19_{t-1}$ & -0.057 & $-2.48^{* *}$ \\
Short run estimates & $W T I_{t-1}$ & -0.808 & $-4.58^{* * *}$ \\
& $S P 500_{t-1}$ & 0.529 & $4.366^{* * *}$ \\
& $V I X_{t-1}$ & -0.006 & -0.680 \\
& $E P U_{t-1}$ & -0.736 & $-3.28^{* * *}$ \\
\hline
\end{tabular}


Precisely, although there is a marginal positive relationship between COVID-19 daily new cases and BTC price in the long-run, the impact of volatility index (VIX) cannot be neglected. If the VIX increases by $1 \%$, the BTC increases approximately by $0.21 \%$, which holds a considerable value and confirms that Bitcoin acts as a hedge for global uncertainty (Bouri et al., 2017). On the other hand, any crash down in WTI oil prices and/or S\&P500 has significant impact on increasing the demand of Bitcoin and thus increases its price. In another words, general price volatility subjected to the oscillations of oil price may depreciate (or appreciate) the price of Bitcoin (Ciaian et al., 2016). In the long-run, S\&P500 has the greatest impact on Bitcoin prices after the VIX, where a decrease of $1 \%$ in stock market prices inflate the price of Bitcoin by $0.18 \%$ (Note 7). The estimated error correction term suggests that the adjustment speed to restore the dynamic of the model after any shock by correcting around $73.6 \%$ within a year.

A similar situation is noticed in the short run, except for the influence of US EPU, which becomes insignificant. Looking at the impact of the daily new cases, the impact in short term is more than the long term. In addition, the inverse relationship shown with the US stock prices -S\&P500 is not surprising given that the period which witnessed a noticeable plunge in stock market prices and thus increased the stress of the financial market, have experienced a remarkable jump in Bitcoin level. Precisely, although an increase of $1 \%$ in the reported new cases increases the price of bitcoins only by $0.004 \%$ in the short run, the direct impact of the decrease in S\&P500 by $1 \%$ can push the prices of the Bitcoins by $0.81 \%$. These results are explaining the reaction of commodity and financial market's reaction to the COVID-19 spread in the glob specially in Europe and the US. The robustness results shown in Table (5) show that the estimation is stable with no serial correlation.

Table 5. Diagnostic tests

\begin{tabular}{ll}
\hline Test & Coefficient \\
\hline$R^{2}$ & 0.74 \\
Adjusted $R^{2}$ & 0.67 \\
F- statistics & $11.105(0.017)$ \\
Jarque-Bera normality test & $1.030(0.308)$ \\
Breusch-Godfrey Serial Correlation LM Test & $0.707(0.306)$ \\
\hline
\end{tabular}

All in all, it is clear that even if the direct positive impact of COVID-19 new infection cases on Bitcoin price might be promising for investors to allow them to fly to another platform, the negative impact on both stock market and the global financial stress cannot be neglected. Given the speed of propagation of this pandemic virus, if the world governments are not proactive, promptly implementing the required measures to isolate the suspected cases of COVID-19, the global economy risk to be paralyzed in few weeks.

\section{Concluding Remarks}

Although the health fears associated with the spread of the new coronavirus outweigh economic concerns, the financial and economic impact cannot be neglected. The spill over has reached many industries and affected the prices of various commodities. However, the market of cryptocurrency has witnessed a remarkable jump in demand which has pushed the price to increase. Many investors had to find another steady temporary landing for a while with less risk. In this context, the purpose this research is to investigate whether the COVID-19 numbers, in terms of daily announcements of new infection cases, has influenced the cryptocurrency market and thus affected bitcoin prices in the short-term. In addition, the existence of long-run relationship among the suggested variables has been examined.

The results of ARDL estimation documented a positive and significant impact of the coronavirus crisis, but relatively small as compared to the effect of financial volatility on bitcoin. The COVID-19 impact on bitcoin seems to be rather indirect, affecting first the stock market prices of the US, where the plunge in S\&P500 causes fears and thus increase the level of financial markets volatility (Albulescu, 2020). The increased prices of bitcoin associated with the fall of S\&P500, which increases the level of stress in the global financial market proves that bitcoin can acts as a 'haven'. Having negative significant relationship between the EPU and bitcoin concludes that bitcoin can serve as a hedging tool against economic policy uncertainty in the long run.

Under the light of the above, fears and low confidence in market associated with the persistence of coronavirus may lead to a dreadful economic contraction. Although couple of countries such as China and New Zealand seem to gain the fight against COVID-19, the virus exponentially propagates in different regions including GCC, Europe and the US. Consequently, a strong coordinated worldwide reaction is required, including economic 
measures to prevent a severe economic downturn. Central banks have already started to cut the interest rates, but this measure should be followed by appropriated fiscal facilities.

\section{References}

Albulescu, C. (2020). Coronavirus and oil price crash. Available at SSRN 3553452. https://doi.org/10.2139/ssrn.3553452

Alkhathlan, K., Gately, D., \& Javid, M. (2014). Analysis of Saudi Arabia's behavior within OPEC and the world oil market. Energy Policy, 64, 209-225. https://doi.org/10.1016/j.enpol.2013.09.030

Al-Yahyaee, K. H., Rehman, M. U., Mensi, W., \& Al-Jarrah, I. M. W. (2019). Can uncertainty indices predict Bitcoin prices? A revisited analysis using partial and multivariate wavelet approaches. The North American Journal of Economics and Finance, 49, 47-56. https://doi.org/10.1016/j.najef.2019.03.019

Antonakakis, N., Chatziantoniou, I., \& Filis, G. (2013). Dynamic co-movements of stock market returns, implied $\begin{array}{lllll}\text { volatility and policy uncertainty. Economics } & \text { Letters, }\end{array}$ https://doi.org/10.1016/j.econlet.2013.04.004

Baker, M. (2016). Statisticians issue warning over misuse of $\mathrm{P}$ values. Nature News, 531(7593), 151. https://doi.org/10.1038/nature.2016.19503

Bouri, E., Gupta, R., Tiwari, A. K., \& Roubaud, D. (2017). Does Bitcoin hedge global uncertainty? Evidence from wavelet-based quantile-in-quantile regressions. Finance Research Letters, 23, 87-95. https://doi.org/10.1016/j.frl.2017.02.009

Chen, C., Liu, L., \& Zhao, N. (2020). Fear sentiment, uncertainty, and bitcoin price dynamics: The case of COVID-19. Emerging Markets Finance and Trade, 56(10), 2298-2309. https://doi.org/10.1080/1540496X.2020.1787150

Chen, X., \& Chiang, T. C. (2020). Empirical investigation of changes in policy uncertainty on stock returnsEvidence from China's market. Research in International Business and Finance, 101183. https://doi.org/10.1016/j.ribaf.2020.101183

Ciaian, P., Rajcaniova, M., \& Kancs, D. A. (2016). The economics of BitCoin price formation. Applied Economics, 48(19), 1799-1815. https://doi.org/10.1080/00036846.2015.1109038

Corbet, S., Larkin, C., \& Lucey, B. (2020). The contagion effects of the covid-19 pandemic: Evidence from gold and cryptocurrencies. Finance Research Letters, 101554. https://doi.org/10.1016/j.frl.2020.101554

Demir, E., Gozgor, G., Lau, C. K. M., \& Vigne, S. A. (2018). Does economic policy uncertainty predict the Bitcoin returns? An empirical investigation. Finance Research Letters, 26, 145-149. https://doi.org/10.1016/j.frl.2018.01.005

Dickey, D. A., \& Fuller, W. A. (1979). Distribution of the estimators for autoregressive time series with a unit root. Journal of the American statistical association, 74(366a), 427-431. https://doi.org/10.1080/01621459.1979.10482531

Hamilton, J. D. (2003). What is an oil shock? Journal of Econometrics, 113(2), 363-398. https://doi.org/10.1016/S0304-4076(02)00207-5

Kilian, L. (2009). Not all oil price shocks are alike: Disentangling demand and supply shocks in the crude oil market. American Economic Review, 99(3), 1053-69. https://doi.org/10.1257/aer.99.3.1053

Kilian, L., \& Murphy, D. P. (2014). The role of inventories and speculative trading in the global market for crude oil. Journal of Applied Econometrics, 29(3), 454-478. https://doi.org/10.1002/jae.2322

Klein, T., Thu, H. P., \& Walther, T. (2018). Bitcoin is not the New Gold-A comparison of volatility, correlation, and portfolio performance. International Review of Financial Analysis, 59, 105-116. https://doi.org/10.1016/j.irfa.2018.07.010

Kwiatkowski, D., Phillips, P. C., Schmidt, P., \& Shin, Y. (1992). Testing the null hypothesis of stationarity against the alternative of a unit root. Journal of Econometrics, 54(1-3), 159-178. https://doi.org/10.1016/0304-4076(92)90104-Y

Mnif, E., Jarboui, A., \& Mouakhar, K. (2020). How the cryptocurrency market has performed during COVID 19? A multifractal analysis. Finance research letters, 36, 101647. https://doi.org/10.1016/j.frl.2020.101647

Narayan, P. K. (2005). The saving and investment nexus for China: evidence from cointegration tests. Applied Economics, 37(17), 1979-1990. https://doi.org/10.1080/00036840500278103 
OPEC. (2020a). Organization for the petroleum exporting countries. Monthly Oil Market Reports. Retrieved from https://www.opec.org/opec ${ }^{\cdot}$ web/

Pesaran, H. H., \& Shin, Y. (1998). Generalized impulse response analysis in linear multivariate models. Economics letters, 58(1), 17-29. https://doi.org/10.1016/S0165-1765(97)00214-0

Pesaran, M. H., \& Pesaran, B. (1997). Working with Microfit 4.0: Interactive econometric analysis. Oxford University Press.

Pesaran, M. H., \& Smith, R. P. (1998). Structural analysis of cointegrating VARs. Journal of Economic Surveys, 12(5), 471-505. https://doi.org/10.1111/1467-6419.00065

Pesaran, M. H., Shin, Y., \& Smith, R. J. (2001). Bounds testing approaches to the analysis of level relationships. Journal of Applied Econometrics, 16(3), 289-326. https://doi.org/10.1002/jae.616

Pesaran, M. H., Shin, Y., \& Smith, R. P. (1999). Pooled mean group estimation of dynamic heterogeneous panels. Journal of the American Statistical Association, 94(446), 621-634. https://doi.org/10.1080/01621459.1999.10474156

Phillips, P. C., \& Perron, P. (1988). Testing for a unit root in time series regression. Biometrika, 75(2), 335-346. https://doi.org/10.1093/biomet/75.2.335

Shahzad, S. J. H., Bouri, E., Roubaud, D., Kristoufek, L., \& Lucey, B. (2019). Is Bitcoin a better safe-haven investment than gold and commodities? International Review of Financial Analysis, 63, 322-330. https://doi.org/10.1016/j.irfa.2019.01.002

Van Wijk, D. (2013). What can be expected from the BitCoin. Erasmus Universiteit Rotterdam.

Zhenghui, L., \& Junhao, Z. (2020). Impact of economic policy uncertainty shocks on China's financial conditions. Finance Research Letters, 35, 101303. https://doi.org/10.1016/j.frl.2019.101303

\section{Notes}

Note 1.

https://www.npr.org/sections/goatsandsoda/2020/03/11/814474930/coronavirus-covid-19-is-now-officially-a-pan demic-who-says

Note 2. For more information, visit: https://covid19. who.int/

Note 3. For more information, visit:

https://www.adb.org/news/covid-19-economic-impact-could-reach-8-8-trillion-globally-new-adb-report

Note 4. Among others, see Hamilton (2003); Killian (2009) and Killian (2014).

Note 5. For details refer to Baker et al. (2016)

Note 6. Data are extracted on 23 May 2020 from http://www.policyuncertainty.com/

Note 7. The recent literature has intensively investigated the relationship between Bitcoin and stock indices. For more information, see Ciaian et al. (2016) and van Wijk (2013), among others.

\section{Copyrights}

Copyright for this article is retained by the author(s), with first publication rights granted to the journal.

This is an open-access article distributed under the terms and conditions of the Creative Commons Attribution license (http://creativecommons.org/licenses/by/4.0/). 